\title{
Evaluation Of Jogja Application Success from User's Perspective Using Development of DeLone and McLean Models To Support The Realization Of The Smart Province
}

Evaluasi Kesuksesan Aplikasi Jogja Istimewa Dari Perspektif Pengguna Menggunakan Pengembangan DeLone and McLean Model Dalam Mendukung Terwujudnya Smart Province

\author{
Angelica Amartya Putri ${ }^{1 *}$, Herlina Jayandianti², Bambang Yuwono ${ }^{3}$ \\ 1,2,3 Sistem Informasi, Universitas Pembangunan Nasional Veteran Yogyakarta, Indonesia \\ 124170011@upnyk.ac.id, ${ }^{2}$ herlina.jayandianti@upnyk.ac.id, ${ }^{3}$ bambangy@upnyk.ac.id \\ *: Penulis korenspondensi (corresponding author)
}

\author{
Informasi Artikel \\ Received: March 2021 \\ Revised: June 2021 \\ Accepted: June 2021 \\ Published: August 2021
}

\begin{abstract}
Purpose: This study aims to measure success and determine the factors that support or hinder the success of the Jogja Istimewa application.

Method: This study uses a modified DeLone and McLean Model 2003. The data used are primary data obtained from interviews with the DISKOMINFO and answers to 125 users of the Jogja Istimewa application as respondents in a distributed questionnaire. The results of the questionnaire were processed using SPSS to test the validity, reliability and normality of the data. After that, the data is processed using Structural Equation Modeling (SEM) to test the inner model and outer model which includes hypothesis testing. Result: There are nine hypotheses tested using the SEM model. Nine hypotheses were proposed, it was stated that five hypotheses were accepted and four other hypotheses were rejected. the Jogja Istimewa application has a high success rate. The factors that are stated to influence the success of the Jogja Istimewa application are Information Quality, Service Quality, System Quality and User Satisfaction. The factors that are stated to hinder the success of the Jogja Istimewa application are Format of Output and Reliability in the Information Quality variable, the System Quality variable in the Language indicator, and the Charges for System Use indicator on the Intention to Use variable. State of the art: Based on previous research, this study has a fairly similar reference but different case studies, indicators, and conceptual models to test hypotheses in addition to knowing the factors that hinder and support the success of the Jogja Istimewa application.
\end{abstract}


Keywords: Delone and Mclean model, Jogja Istimewa, Success Evaluation, SEM

Kata kunci: Model Delone dan Mclean, Jogja Istimewa, Evaluasi Kesuksesan, SmartPLS

\begin{abstract}
Abstrak
Tujuan: Penelitian ini bertujuan untuk mengetahui faktorfaktor yang menghambat keberhasilan aplikasi Jogja Istimewa, mengukur keberhasilannya, sekaligus memberi rekomendasi strategis untuk meningkatkan kesuksesan aplikasi Jogja Istimewa dan mengetahui hubungan antar variabel.

Metode: Penelitian ini mengadaptasi pengembangan DeLone dan McLean Model 2003. Data yang digunakan adalah data primer yang diperoleh dari wawancara dengan DISKOMINFO dan jawaban 125 pengguna aplikasi Jogja Istimewa sebagai responden dalam kuesioner yang disebarkan. Hasil angket diolah menggunakan SPSS untuk menguji normalitas data. Setelah itu data diolah menggunakan Structural Equation Modeling (SEM) untuk pengujian inner model dan outer model yang meliputi pengujian hipotesis melalui software SmartPLS.

Hasil: Dari sembilan hipotesis yang diajukan, lima hipotesis diterima dan empat hipotesis lainnya ditolak. Dikarenakan tidak semua variabel saling mempengaruhi signifikan maka aplikasi Istimewa Jogja ini dinyatakan belum sukses. Faktor-faktor yang menjadi penghambat keberhasilan aplikasi Jogja Istimewa adalah indikator Format Output dan Reliability pada variabel Kualitas Informasi; indikator Language, fungsi fitur yang tidak berjalan semestinya,dan pengelola lambat melakukan perbaikan pada variabel Kualitas Sistem; indikator tangibles, assurance, dan responsiveness pada variabel Kualitas Layanan.

State of the art: Berdasarkan penelitian terdahulu, penelitian ini memiliki karakteristik yang cukup mirip namun berbeda studi kasus, indikator, dan model konseptual untuk menguji hipotesis dengan tambahan untuk mengetahui faktor yang menghambat kesuksesan aplikasi Jogja Istimewa dan hubungan antar variabel.
\end{abstract}

\section{Pendahuluan}

Smart province merupakan konsep provinsi yang memanfaatkan teknologi digital dengan tujuan untuk memperbaiki pelayanan publik dan juga meningkatkan kesejahteraan masyarakat dalam mendukung terwujudnya kualitas kehidupan yang lebih modern dan meningkatkan manajemen kota [2]. Pemerintah Daerah DIY menggandeng PT Gamatechno Indonesia untuk menciptakan salah satu smart province platform yang dapat mengenalkan Jogja (pariwisata, sejarah dan budaya DIY serta informasi-informasi penting lainnya) secara digital kepada masyarakat yaitu aplikasi Jogja Istimewa. Disisi lain, peran aplikasi Jogja Istimewa yaitu untuk mempermudah 
Pemerintah Daerah DIY dalam pemberian informasi sekaligus meningkatkan pelayanan terhadap masyarakat khususnya masyarakat lokal DIY maupun masyarakat pendatang yang berkunjung ataupun tinggal di DIY.

Untuk mewujudkan aplikasi yang baik maka perlu dilakukan evaluasi untuk mengetahui bagaimana implementasi suatu aplikasi yang telah dijalankan, bagaimana dampak serta manfaatnya terhadap pengguna maupun perusahaan. Evaluasi suatu aplikasi telah dilakukan oleh Sarasati \& Madyatmadja (2020) menggunakan metode Technology Acceptance Model (TAM) dimana metode ini menjelaskan bahwa manfaat serta kemudahan penggunaan menentukan niat individu dalam menggunakan sistem. Aplikasi yang dievaluasi yaitu LAKSA yang merupakan aplikasi yang dikelola Diskominfo Kota Tangerang yang disediakan untuk menjadi salah satu pelayanan publik dalam mendengar aspirasi masyarakat setempat. Selain itu, evaluasi aplikasi juga dapat dilakukan menggunakan metode Task Technology Fit (TTF) seperti yang telah dilakukan Aurealia \& Siregar (2017) dalam menganalisis teknologi pendukung kinerja dosen dimana metode TTF tersebut berfokus pada kemampuan teknologi informasi untuk memberikan dukungan terhadap pekerjaan. Selanjutnya, evaluasi aplikasi dapat dilakukan dengan metode End User Computing Satisfaction yang telah dilakukan oleh Rahman \& Hartawan Syarif (2019) yang menguji user interface aplikasi safe travel milik kementerian luar negeri RI. Metode EUCS merupakan metode untuk mengukur tingkat kepuasan pengguna suatu aplikasi dimana pengguna tersebut mengevaluasi aplikasi tersebut berdasarkan pengalaman user dalam menggunakan aplikasi itu sendiri. Menurut Laudon (2000), faktor manusia, teknologi, dan organisasi sangat menentukan keberhasilan maupun kegagalan dari suatu sistem informasi. Namun, metode dari penelitian yang telah dijabarkan diatas memiliki keterbatasan terkait hubungan antara faktor yang diteliti terhadap penggunaan sistem, dalam artian metode Technology Acceptance Model (TAM), Task Technology Fit (TTF), End User Computing Satisfaction (EUCS) tidak mencakup hubungan faktor manusia, organisasi, dan teknologi terhadap penggunaan sistem.

Model DeLone dan McLean memberikan pemahaman komprehensif tentang keberhasilan sistem informasi dan telah diterima secara luas sebagai model komprehensif untuk menilai sistem informasi, bentuk akhir dari model ini adalah kualitas sistem, kualitas informasi, kualitas layanan, kegunaan, kepuasan pengguna dan manfaatnya [11]. Menurut Jaafreh (2017), Model DeLone dan McLean merupakan upaya paling awal untuk mengukur kinerja suatu sistem informasi dan juga dapat menjelaskan sekaligus memprediksi faktor-faktor yang berkontribusi pada keberhasilan sistem informasi [8]. Sehingga dapat disimpulkan bahwa penggunaan Model DeLone dan McLean adalah metode penelitian yang tepat dalam mengevaluasi aplikasi Jogja Istimewa dimana metode ini dapat mengukur kesuksesan aplikasi yang mencakup hubungan faktor manusia, organisasi, dan teknologi terhadap penggunaan sistem dinilai dari enam variabel yang saling berdampak satu sama lain yaitu kualitas aplikasi, kualitas informasi, kualitas sistem, dampak individual, dampak organisasional, kepuasan pengguna, dan intensitas penggunaan.

Pengembangan dari Model DeLone dan McLean telah banyak dilakukan dari segi modifikasi model konseptual serta pengembangan indikatornya. Penelitian yang dilakukan Iivari (2005) memodifikasi model konseptual Model DeLone dan McLean yang dipublikasikan tahun 1992 sekaligus mengembangkan indikator-indikator dari Model DeLone dan McLean untuk meneliti hubungan antar variabel dalam Oulu City Council's application package. Yi-Shun Wanga \& YiWen Liao (2008) juga melakukan penelitian dengan mengembangkan Model DeLone dan 
McLean untuk mengukur keberhasilan sistem e-government G2C dari perspektif warga. Penelitan tersebut menggunakan model konseptual Model DeLone dan McLean 2003 yang dimodifikasi. Dari penjelasan tersebut, maka penelitian ini menggunakan pengembangan model konseptual dari Model DeLone dan McLean mengadaptasi Yi-Shun Wanga \& Yi-Wen Liao (2008).

\section{Metode/Perancangan}

Metodologi penelitian yang akan digunakan dalam penelitian ini adalah metode penelitian kuantitatif dengan studi kasus aplikasi Jogja Istimewa yang dikelola Dinas Komunikasi dan Informatika DISKOMINFO DIY. Penggunaan metode penelitian kuantitatif didasari dengan adanya pengambilan data dan analisis terhadap data yang diambil serta metode kualitatif didasari dengan adanya pengambilan data melalui wawancara terhadap pihak Dinas Komunikasi dan Informatika. Data penelitian yang digunakan merupakan data primer berupa data kuesioner terhadap pengguna aplikasi Jogja Istimewa serta wawancara terhadap pihak Dinas Komunikasi dan Informatika DISKOMINFO DIY. Software yang digunakan dalam pengambilan data dan pengolahan data yaitu Google Form, Microsoft Excel, SPSS, dan SmartPLS. Dalam hal ini Google Form dan Microsoft Excel digunakan untuk penyebaran sekaligus pengumpulan data. Data yang telah dikumpulkan akan dipilah lalu dilakukan pengolahan data statistika pada software SPSS. Pengujian statistika ini meliputi uji normalitas. Uji validitas dan reliabilitas dilakukan dengan tujuan untuk mengetahui data yang dimiliki bernilai valid dan reliabel, hal ini sangat penting karena valid dan reliabel merupakan syarat untuk bisa melanjutkan ke tahap analisis berikutnya. Setelah uji asumsi kualitas pengukuran tersebut telah sesuai dan memenuhi syarat, maka tahap selanjutnyaSelanjutnya dilakukan pengujian hipotesis menggunakan software SmartPLS. Pengujian hipotesis meliputi outer model yang menguji hubungan antara indikator dengan variabel latennya dan inner model yang menguji hubungan antar variabel laten. Model konseptual dalam penelitian ini dapat dilihat pada Gambar 1. Indikator yang digunakan dapat dilihat pada Tabel 1.

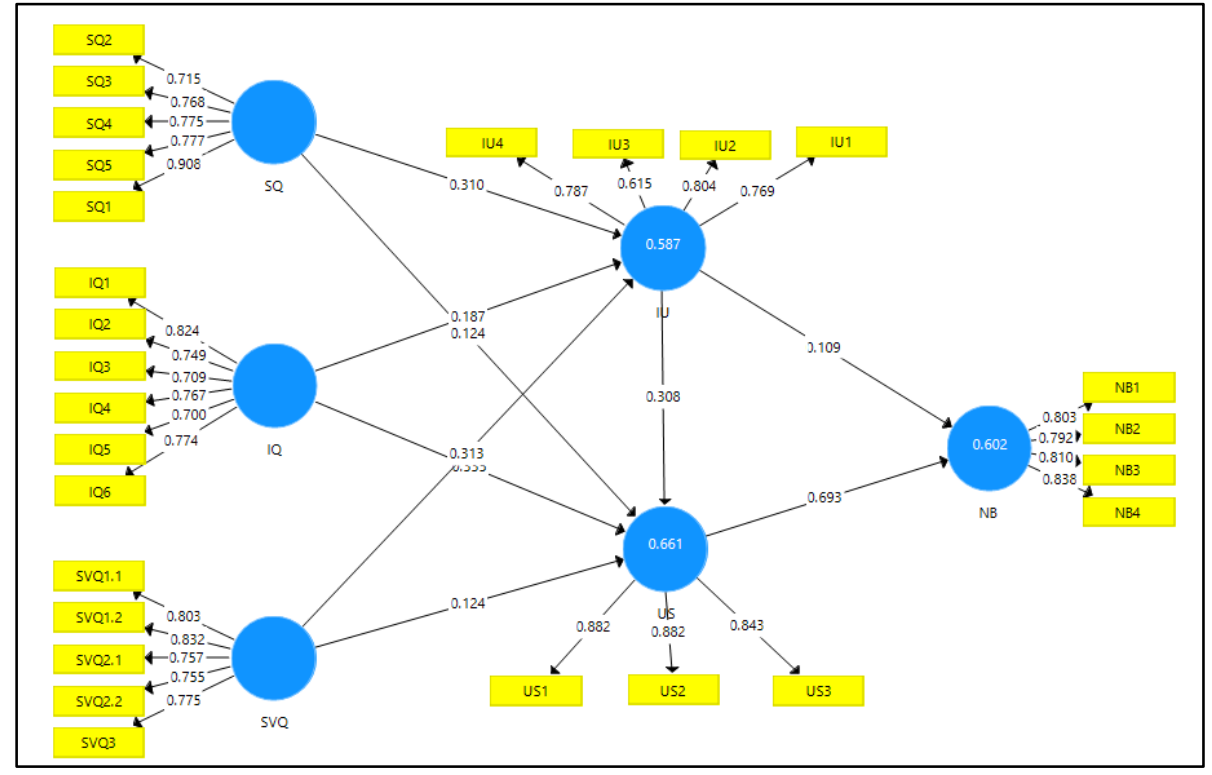

Gambar 1. Model Konseptual Penelitian 
Tabel 1 Variabel dan indikator penelitian

\begin{tabular}{|c|c|c|c|c|}
\hline Variabel & Indikator & & Penjelasan & Referensi \\
\hline \multirow{6}{*}{$\begin{array}{l}\text { Information } \\
\text { Quality/Kualitas } \\
\text { Informasi }\end{array}$} & IQ1 & Completeness & $\begin{array}{l}\text { Pengguna aplikasi mendapat data } \\
\text { yang lengkap sesuai kebutuhan. }\end{array}$ & $\begin{array}{l}\text { (DeLone \& } \\
\text { McLean, 2003) }\end{array}$ \\
\hline & IQ2 & Understandability & $\begin{array}{l}\text { Informasi yang diberikan } \\
\text { aplikasi mudah dipahami. }\end{array}$ & $\begin{array}{l}\text { (DeLone \& } \\
\text { McLean, 2003) }\end{array}$ \\
\hline & IQ3 & Reliability & \begin{tabular}{lcr} 
Informasi & yang & \multicolumn{2}{r}{ diberikan } \\
aplikasi akurat dan & tidak \\
mengandung berita palsu. & \\
\end{tabular} & $\begin{array}{l}\text { (DeLone \& } \\
\text { McLean, 2003) }\end{array}$ \\
\hline & IQ4 & Currency & $\begin{array}{l}\text { Data yang pengguna aplikasi } \\
\text { dapat merupakan informasi yang } \\
\text { terkini dan selalu diperbaharui. }\end{array}$ & $\begin{array}{l}\text { (DeLone \& } \\
\text { McLean, 2003) }\end{array}$ \\
\hline & IQ5 & Format of Output & $\begin{array}{l}\text { Data yang Pengguna aplikasi } \\
\text { dapatkan dapat digunakan di alat } \\
\text { atau media lain. }\end{array}$ & (Iivari, 2005) \\
\hline & IQ6 & Content & $\begin{array}{lrr}\text { Informasi } & \text { yang } & \text { diberikan } \\
\text { aplikasi } & \text { kepada } & \text { pengguna } \\
\text { merupakan } & \text { informasi } & \text { yang } \\
\text { berkualitas. } & & \\
\end{array}$ & $\begin{array}{l}\text { (DeLone \& } \\
\text { McLean, 2003) }\end{array}$ \\
\hline \multirow{5}{*}{$\begin{array}{l}\text { Service } \\
\text { Quality/Kualitas } \\
\text { Layanan }\end{array}$} & SVQ1.1 & Assurance & \multirow{2}{*}{$\begin{array}{l}\text { Pengguna aplikasi merasa aman } \\
\text { dalam mengakses atau mengirim } \\
\text { data melalui sistem. }\end{array}$} & $\begin{array}{l}\text { (DeLone \& } \\
\text { McLean, 2003) }\end{array}$ \\
\hline & SVQ1.2 & & & \\
\hline & SVQ2.1 & \multirow[t]{2}{*}{ Responsiveness } & \multirow{2}{*}{$\begin{array}{l}\text { Sistem memberikan tanggapan } \\
\text { sesuai dengan apa yang } \\
\text { pengguna aplikasi butuhkan } \\
\text { secara cepat dan tepat. }\end{array}$} & $\begin{array}{l}\text { (DeLone \& } \\
\text { McLean, 2003) }\end{array}$ \\
\hline & SVQ2.2 & & & \\
\hline & SVQ3 & Tangibles & $\begin{array}{l}\text { Tampilan fisik aplikasi yang } \\
\text { diberikan pengembang aplikasi } \\
\text { tidak membuat bingung } \\
\text { pengguna. }\end{array}$ & $\begin{array}{l}\text { (DeLone \& } \\
\text { McLean, 2003) }\end{array}$ \\
\hline \multirow[t]{2}{*}{$\begin{array}{l}\text { System Quality } \\
\text { Kualitas Sistem }\end{array}$} & SQ1 & Ease of Use & $\begin{array}{l}\text { Kemudahan pengguna aplikasi } \\
\text { dalam menggunakan aplikasi. }\end{array}$ & $\begin{array}{l}\text { (DeLone \& } \\
\text { McLean, 2003) }\end{array}$ \\
\hline & SQ2 & Language & $\begin{array}{l}\text { Pengguna aplikasi dapat dengan } \\
\text { mudah mengerti bahasa yang } \\
\text { dimaksud oleh sistem. }\end{array}$ & (Iivari, 2005) \\
\hline \multirow[t]{3}{*}{$\begin{array}{l}\text { System Quality } \\
\text { Kualitas Sistem }\end{array}$} & SQ3 & $\begin{array}{l}\text { Recovery of an } \\
\text { error }\end{array}$ & $\begin{array}{l}\text { Sistem memberikan fasilitas } \\
\text { perbaikan jika terjadi kegagalan } \\
\text { sistem. }\end{array}$ & (Iivari, 2005) \\
\hline & SQ4 & Response Time & $\begin{array}{l}\text { Pengguna aplikasi tidak perlu } \\
\text { waktu yang lama untuk mendapat } \\
\text { informasi setelah mengakses } \\
\text { sistem. }\end{array}$ & $\begin{array}{l}\text { (DeLone \& } \\
\text { McLean, 2003) }\end{array}$ \\
\hline & SQ5 & $\begin{array}{l}\text { Usefullness of } \\
\text { System Features } \\
\text { and Functions }\end{array}$ & $\begin{array}{l}\text { Mayoritas fungsi dan fitur } \\
\text { berguna bagi pengguna. }\end{array}$ & $\begin{array}{lr}\text { Gable } & \text { et al. } \\
(2008), & \text { Sedera } \\
\text { and } & \text { Gable } \\
(2004) & \end{array}$ \\
\hline \multirow[t]{2}{*}{$\begin{array}{l}\text { Intention To } \\
\text { Use/Penggunaan }\end{array}$} & IU1 & Regularity of Use & $\begin{array}{l}\text { Pengguna aplikasi rutin } \\
\text { mengakses sistem. }\end{array}$ & $\begin{array}{l}\text { (DeLone \& } \\
\text { McLean, 2003) }\end{array}$ \\
\hline & IU2 & Ammount of Use & $\begin{array}{l}\text { Pengguna aplikasi menggunakan } \\
\text { aplikasi tersebut dalam waktu } \\
\text { yang lama }\end{array}$ & $\begin{array}{l}\text { (DeLone \& } \\
\text { McLean, 2003) }\end{array}$ \\
\hline
\end{tabular}




\begin{tabular}{|c|c|c|c|c|}
\hline & IU3 & $\begin{array}{l}\text { Charges } \\
\text { System Use }\end{array}$ & $\begin{array}{l}\text { Pengguna aplikasi menggunakan } \\
\text { aplikasi tersebut secara gratis. }\end{array}$ & $\begin{array}{l}\text { (DeLone \& } \\
\text { McLean, 2003) }\end{array}$ \\
\hline & IU4 & Intention to reuse & $\begin{array}{l}\text { Keinginan pengguna untuk } \\
\text { menggunakan aplikasi tersebut } \\
\text { kembali. }\end{array}$ & $\begin{array}{l}\text { Davis (1989), } \\
\text { Wang (2008) }\end{array}$ \\
\hline \multirow[t]{3}{*}{$\begin{array}{l}\text { User Satisfaction/ } \\
\text { Kepuasan } \\
\text { Pengguna }\end{array}$} & US1 & $\begin{array}{l}\text { Information } \\
\text { satisfaction }\end{array}$ & $\begin{array}{l}\text { Kepuasan pengguna aplikasi } \\
\text { dalam mendapat informasi yang } \\
\text { didapat dari aplikasi. }\end{array}$ & $\begin{array}{l}\text { (DeLone \& } \\
\text { McLean, 2003) }\end{array}$ \\
\hline & US2 & $\begin{array}{l}\text { Overall } \\
\text { satisfaction }\end{array}$ & $\begin{array}{l}\text { Kepuasan Pengguna } \\
\text { dalam menggunakan } \\
\begin{array}{l}\text { secara keseluruhan. } \\
\text { sistem }\end{array}\end{array}$ & $\begin{array}{l}\text { (DeLone \& } \\
\text { McLean, 2003) }\end{array}$ \\
\hline & US3 & Enjoyment & $\begin{array}{l}\text { Menggunakan aplikasi } \\
\text { menyenangkan untuk pengguna } \\
\text { aplikasi tersebut. }\end{array}$ & $\begin{array}{l}\text { (DeLone \& } \\
\text { McLean, 2003) }\end{array}$ \\
\hline \multirow[t]{4}{*}{$\begin{array}{l}\text { Net Benefit/ } \\
\text { Dampak Individual }\end{array}$} & NB1 & $\begin{array}{l}\text { Decision } \\
\text { Effectiveness }\end{array}$ & $\begin{array}{l}\text { Fasilitas dalam aplikasi dapat } \\
\text { membantu pengguna dalam } \\
\text { pengambilan keputusan yang } \\
\text { efektif. }\end{array}$ & $\begin{array}{lr}\text { Gable } & \text { et al. } \\
(2008), & \text { Sedera } \\
\text { and } & \text { Gable } \\
(200 b) & \\
\end{array}$ \\
\hline & NB2 & $\begin{array}{l}\text { Improved } \\
\text { Individual } \\
\text { Productivity }\end{array}$ & $\begin{array}{l}\text { Aplikasi dapat membantu } \\
\text { produktivitas pengguna. }\end{array}$ & $\begin{array}{l}\text { (DeLone \& } \\
\text { McLean, 2003) }\end{array}$ \\
\hline & NB3 & Learning & $\begin{array}{l}\text { Pengguna mendapat ilmu dengan } \\
\text { menggunakan aplikasi. }\end{array}$ & $\begin{array}{l}\text { (DeLone \& } \\
\text { McLean, 2003) }\end{array}$ \\
\hline & NB4 & Usefulness & $\begin{array}{ll}\text { Aplikasi memberikan } & \text { kegunaan } \\
\text { yang signifikan } & \text { terhadap } \\
\text { pengguna. }\end{array}$ & (Iivari, 2005) \\
\hline
\end{tabular}

\subsection{Uji Statistika}

Setelah mendapatkan data-data dari kuesioner yang telah disebarkan, maka dilakukan uji stastika menggunakan SPSS.

Dalam penelitian ini akan dilakukan statistik deskriptif terhadap data penelitian dan responden. Hasil uji deksriptif dapat dilihat pada Tabel 2.

Tabel 2 Uji deskriptif

\begin{tabular}{|c|c|c|c|c|c|}
\hline & Frekuensi & Presentase & & Frekuensi & Presentase \\
\hline Jenis Pekerjaan & & & Jenis Menu & & \\
\hline Pegawai Negeri & 27 & $21,6 \%$ & E-Lapor & 14 & $11,2 \%$ \\
\hline Pegawai Swasta & 1 & $0,8 \%$ & Streaming & 24 & $19,2 \%$ \\
\hline Siswa/Mahasiswas & 92 & $73,6 \%$ & Galeri & 45 & $36,0 \%$ \\
\hline TNI & 1 & $0,8 \%$ & Layanan Publik & 47 & $37,6 \%$ \\
\hline Wirausaha & 2 & $1,6 \%$ & Wisata & 83 & $66,4 \%$ \\
\hline Ibu/Bapak Rumah Tangga & 1 & $0,8 \%$ & Kuliner & 79 & $63,2 \%$ \\
\hline Jenis Kelamin & & & Event & 32 & $25,6 \%$ \\
\hline Laki-Laki & 61 & $48,8 \%$ & Rentang Umur & & \\
\hline Perempuan & 64 & $51,2 \%$ & Kurang 21 tahun & 69 & $55,2 \%$ \\
\hline Lama Penggunaan & & & $21-30$ tahun & 23 & $18,4 \%$ \\
\hline Kurang 1 Bulan & 70 & $56,0 \%$ & $31-40$ tahun & 0 & $0,0 \%$ \\
\hline $1-2$ Bulan & 39 & $31,2 \%$ & $41-50$ tahun & 24 & $19,2 \%$ \\
\hline Lebih 2 Bulan & 16 & $12,8 \%$ & & & \\
\hline
\end{tabular}




\subsection{Uji SEM}

\section{a. Inner Model}

\section{Validitas Konvergen}

Jika nilai koefisien jalur antara 0,5 - 0,6 maka dikatakan cukup, dan jika nilai koefisien jalur $\geq$ 0,7 maka dikatakan tinggi [5] dan Nilai Average Variance Extracted (AVE), nilai AVE yang diharapkan adalah $\geq 0,5$ [13]. Berikut disajikan hasil dari uji validitas konvergen pada Tabel 3.

Tabel 3. Uji validitas konvergen

\begin{tabular}{|c|c|c|c|c|}
\hline Indikator & Loading factor & AVE & $\begin{array}{l}\mathrm{AVE} \geq 0,5 \text { dan } \\
\text { Loading factor } \geq \\
0,6\end{array}$ & Keterangan \\
\hline SQ1 & 0.908 & \multirow{5}{*}{0.626} & Terpenuhi & Valid \\
\hline$\overline{\mathrm{SQ} 2}$ & 0.715 & & Terpenuhi & Valid \\
\hline SQ3 & 0.768 & & Terpenuhi & Valid \\
\hline SQ4 & 0.775 & & Terpenuhi & Valid \\
\hline SQ5 & 0.777 & & Terpenuhi & Valid \\
\hline IQ1 & 0.824 & \multirow{6}{*}{0.570} & Terpenuhi & Valid \\
\hline IQ2 & 0.749 & & Terpenuhi & Valid \\
\hline IQ3 & 0.709 & & Terpenuhi & Valid \\
\hline IQ4 & 0.767 & & Terpenuhi & Valid \\
\hline IQ5 & 0.700 & & Terpenuhi & Valid \\
\hline IQ6 & 0.774 & & Terpenuhi & Valid \\
\hline SVQ1.1 & 0.803 & \multirow{5}{*}{0.616} & Terpenuhi & Valid \\
\hline$\overline{\text { SVQ1.2 }}$ & 0.832 & & Terpenuhi & Valid \\
\hline SVQ2.1 & 0.757 & & Terpenuhi & Valid \\
\hline SVQ2.2 & 0.755 & & Terpenuhi & Valid \\
\hline SVQ3 & 0.775 & & Terpenuhi & Valid \\
\hline IU1 & 0.769 & \multirow{4}{*}{0.559} & Terpenuhi & Valid \\
\hline IU2 & 0.804 & & Terpenuhi & Valid \\
\hline IU3 & 0.615 & & Terpenuhi & Valid \\
\hline IU4 & 0.787 & & Terpenuhi & Valid \\
\hline US1 & 0.882 & \multirow{3}{*}{0.755} & Terpenuhi & Valid \\
\hline US2 & 0.882 & & Terpenuhi & Valid \\
\hline US3 & 0.843 & & Terpenuhi & Valid \\
\hline NB1 & 0.803 & \multirow{4}{*}{0.658} & Terpenuhi & Valid \\
\hline NB2 & 0.792 & & Terpenuhi & Valid \\
\hline NB3 & 0.810 & & Terpenuhi & Valid \\
\hline NB4 & 0.838 & & Terpenuhi & Valid \\
\hline
\end{tabular}

\section{Validitas Diskriminan}

Validitas Diskriminan merupakan model pengukuran dengan refleksif indicator dinilai berdasarkan crossloading pengukuran dengan konstruk. Jika korelasi konstruk dengan item pengukuran lebih besar daripada ukuran konstruk lainnya, maka menunjukan ukuran blok mereka lebih baik dibandingkan dengan blok lainnya [6]. Berikut disajikan hasil dari uji validitas konvergen pada Tabel 4. 
Tabel 4. Uji validitas diskriminan

\begin{tabular}{lllllll}
\multirow{2}{*}{ INDIKATOR } & \multicolumn{7}{c}{ VARIABEL } \\
\cline { 2 - 7 } & IQ & IU & NB & SQ & SVQ & US \\
\hline IQ1 & 0.824 & 0.588 & 0.645 & 0.670 & 0.718 & 0.605 \\
\hline IQ2 & 0.749 & 0.544 & 0.486 & 0.694 & 0.661 & 0.591 \\
\hline IQ3 & 0.709 & 0.453 & 0.522 & 0.565 & 0.574 & 0.481 \\
\hline IQ4 & 0.767 & 0.556 & 0.562 & 0.692 & 0.653 & 0.634 \\
\hline IQ6 & 0.700 & 0.494 & 0.534 & 0.553 & 0.602 & 0.487 \\
\hline IU1 & 0.774 & 0.574 & 0.585 & 0.558 & 0.663 & 0.631 \\
\hline IU2 & 0.477 & 0.769 & 0.415 & 0.495 & 0.504 & 0.422 \\
\hline IU3 & 0.577 & 0.804 & 0.542 & 0.585 & 0.499 & 0.552 \\
\hline IU4 & 0.474 & 0.615 & 0.387 & 0.409 & 0.517 & 0.538 \\
\hline NB1 & 0.581 & 0.787 & 0.471 & 0.644 & 0.648 & 0.633 \\
\hline NB2 & 0.677 & 0.518 & 0.803 & 0.650 & 0.635 & 0.633 \\
\hline NB3 & 0.525 & 0.478 & 0.792 & 0.503 & 0.479 & 0.577 \\
\hline NB4 & 0.597 & 0.474 & 0.810 & 0.489 & 0.548 & 0.659 \\
\hline SQ1 & 0.587 & 0.518 & 0.838 & 0.421 & 0.510 & 0.632 \\
\hline SQ2 & 0.727 & 0.602 & 0.537 & 0.908 & 0.710 & 0.639 \\
\hline SQ3 & 0.587 & 0.436 & 0.451 & 0.715 & 0.573 & 0.481 \\
\hline SQ4 & 0.635 & 0.658 & 0.416 & 0.768 & 0.615 & 0.570 \\
\hline SQ5 & 0.649 & 0.568 & 0.619 & 0.775 & 0.640 & 0.575 \\
\hline SVQ1.1 & 0.660 & 0.573 & 0.493 & 0.777 & 0.729 & 0.591 \\
\hline SVQ1.2 & 0.743 & 0.632 & 0.598 & 0.758 & 0.803 & 0.581 \\
\hline SVQ2.1 & 0.679 & 0.631 & 0.511 & 0.668 & 0.832 & 0.625 \\
\hline SVQ2.2 & 0.650 & 0.540 & 0.524 & 0.601 & 0.757 & 0.596 \\
\hline SVQ3 & 0.676 & 0.547 & 0.573 & 0.577 & 0.755 & 0.571 \\
\hline US1 & 0.663 & 0.669 & 0.666 & 0.587 & 0.661 & 0.882 \\
\hline US2 & 0.695 & 0.652 & 0.672 & 0.706 & 0.646 & 0.882 \\
\hline US3 & 0.629 & 0.573 & 0.676 & 0.599 & 0.619 & 0.843 \\
\hline & & & & & & \\
\hline
\end{tabular}

Croanbach Alpha dan Composite Realiability

Konstruk dinyatakan reliable jika nilai composite reliability maupun cronbach alpha di atas 0,70 [4]. Berikut disajikan hasil dari uji validitas konvergen pada Tabel 5. 
Tabel 5. Uji reliabilitas

\begin{tabular}{llll} 
Variabel & Croanbach Alpha & Composite Reliability & Keterangan \\
\hline IQ & 0,849 & 0,888 & Reliabel \\
\hline SQ & 0,732 & 0,834 & Reliabel \\
\hline SVQ & 0,826 & 0,885 & Reliabel \\
\hline IU & 0,849 & 0,893 & Reliabel \\
\hline US & 0,844 & 0,889 & Reliabel \\
\hline NB & 0,838 & 0,903 & Reliabel \\
\hline
\end{tabular}

\section{b. Outer Model}

\section{R Square}

Perubahan nilai R-Square dapat digunakan untuk menjelaskan pengaruh variabel laten eksogen tertentu terhadap variabel laten endogen apakah mempunyai pengaruh yang substantive. Nilai RSquare 0,75, 0,50 dan 0,25 dapat disimpulkan bahwa model kuat, moderate dan lemah [4]. Nilai R Square dapat dilihat pada Tabel 6.

\section{$Q$ Square}

Nilai Q2 0,002, 0,15 dan 0,35 menunjukan bahwa model lemah, moderat, kuat. Nilai Q2 > 0 menunjukan bawa model memiliki predictive relevance, sengakan Q2 $<0$ menunjukan bahwa model kurang memiliki predictive relevance [4]. Nilai Q Square dapat dilihat pada Tabel 6.

Tabel 6. Uji R Square dan Q Square

\begin{tabular}{lll} 
Variabel & R Square & Q Square \\
\hline IQ & 0 & 0,397 \\
\hline SQ & 0 & 0,431 \\
\hline SVQ & 0 & 0,42 \\
\hline IU & 0,587 & 0,27 \\
\hline NB & 0,602 & 0,421 \\
\hline US & 0,661 & 0,49 \\
\hline
\end{tabular}

\section{Path Coefficient}

Hasil dari uji hipotesis dapat dilihat pada gambar dibawah ini. Nilai t-statistik dan p-value dilihat dari bootstraping, sedangkan nilai path coefficient dilihat dari PLS Algorithm. Hasil uji path coefficient dapat dilihat pada Tabel 7.

Tabel 7. Uji koefisien jalur

\begin{tabular}{ccccccccc} 
Hipotesis & $\begin{array}{c}\text { Path } \\
\text { Coefficient }\end{array}$ & Keterangan & T-Statistics & P-Values & $\begin{array}{c}\text { Nilai T-Statistik } \\
\text { 1,96 dan } \\
\text { P-Values } 0 \mathbf{0 , 0 5}\end{array}$ & Keterangan & Status Hipotesis \\
\hline H1: & IQ $\rightarrow$ IU & 0.187 & Positif & 1.292 & 0.197 & Tidak terpenuhi & Tidak Signifikan & Ditolak \\
\hline H2: & IQ $\rightarrow$ US & 0.335 & Positif & 2.238 & 0.026 & Terpenuhi & Signifikan & Diterima \\
\hline H3: & SQ $\rightarrow$ IU & 0.310 & Positif & 2.326 & 0.020 & Terpenuhi & Signifikan & Diterima \\
\hline H4: & SQ $\rightarrow$ US & 0.124 & Positif & 0.944 & 0.346 & Tidak terpenuhi & Tidak Signifikan & Ditolak \\
\hline H5: & SVQ $\rightarrow$ IU & 0.313 & Positif & 2.055 & 0.040 & Terpenuhi & Signifikan & Diterima \\
\hline H6: & SVQ $\rightarrow$ US & 0.124 & Positif & 0.976 & 0.329 & Tidak terpenuhi & Tidak Signifikan & Ditolak \\
\hline H7: & IU $\rightarrow$ US & 0.109 & Positif & 3.594 & 0.000 & Terpenuhi & Signifikan & Diterima \\
\hline H8: & IU $\rightarrow$ NB & 0.308 & Positif & 1.170 & 0.243 & Tidak terpenuhi & Tidak Signifikan & Ditolak \\
\hline H9: & US $\rightarrow$ NB & 0.693 & Positif & 7.667 & 0.000 & Terpenuhi & Signifikan & Diterima \\
\hline
\end{tabular}




\section{Hasil dan Pembahasan}

\subsection{Pengujian Hipotesis}

Uji hipotesis pada bagian ini akan diuraikan berdasarkan hasil dari path coefficient (Tabel 7) yang telah dilakukan uji oleh peneliti menggunakan aplikasi smartPLS. Berdasarkan data yang disajikan dalam Tabel 7 diketahui bahwa nilai estimate yang didapatkan antar konstruk yaitu positif (+) dan nilai dari T Statistics dan P Values yang bernilai signifikan atau tidak diketahui melalui T Statistics harus lebih besar dari $\mathrm{T}$ tabel dan $\mathrm{P}$ Values harus lebih kecil dari 0,05. Berdasarkan sembilan hipotesis yang diajukan, dinyatakan lima hipotesis diterima yaitu $\mathrm{H} 2, \mathrm{H} 3, \mathrm{H} 5, \mathrm{H} 7$, dan $\mathrm{H} 9$ terbukti bernilai positif dan signifikan. Dari hasil uji hipotesis tersebut diketahui bahwa kualitas sistem dan kualitas layanan mempengaruhi adanya niat pengguna. Kepuasan pengguna dipengaruhi oleh kualitas informasi sekaligus niat pengguna. Kepuasan pengguna memiliki pengaruh yang signifikan terhadap dampak individual.

\subsection{Faktor Yang Menghambat Kesuksesan Aplikasi Jogis}

Faktor-faktor yang dinyatakan menghambat kesuksesan aplikasi Jogja Istimewa berdasarkan perspektif pengguna sejauh ini yaitu Format of Output serta Reliability dalam variabel Information Quality dengan loading factor 0,700 dan 0,709 yang menyatakan bahwa informasi yang didapat pengguna kurang dapat digunakan di media/alat lain dan kurang akurat. Disamping itu, informasi yang disajikan pada aplikasi Jogja Istimewa hanya bersifat faktual, sedangkan jenis informasi yang bersifat opini/menghibur tidak ada. Tingginya penggunaan suatu aplikasi, sosial media salah satunya, didasari dengan adanya opsi untuk menuangkan opini pribadi dan mendapat feedback dari pengguna lain. Pada variabel System Quality pada indikator Language juga menjadi fokus penghambat kesuksesan aplikasi Jogja Istimewa dengan nilai 0,715 yang menyatakan bahwa pengguna tidak mudah mengerti bahasa yang diberikan aplikasi Jogja Istimewa. Selain itu, beberapa fungsi dan fitur pada aplikasi Jogja Istimewa tidak berjalan semestinya dan pihak pengelola lambat untuk melakukan perbaikan jika terjadi kegagalan sistem. Beberapa responden yang merupakan pengguna aplikasi Jogja Istimewa mengeluhkan user interface yang kurang menarik dari aplikasi Jogja Istimewa tersebut, pengguna juga merasa sulit menghubungi pengelola aplikasi Jogja Istimewa ketika ada masalah, dan sistem Jogja Istimewa kurang dalam memberikan tanggapan sesuai dengan apa yang pengguna lakukan. Hal tersebut terlihat dari nilai rata-rata jawaban responden yang rendah pada tiap indikator pada Service Quality. Selanjutnya terdapat pada indikator Charges for System Use pada variabel Intention to Use dengan nilai 0,615 yang menyatakan bahwa dalam menggunakan aplikasi Jogja Istimewa tersebut, pengguna tidak mengaksesnya secara gratis atau dalam artian masih menggunakan kuota. Nilai tersebut dilihat dari loading factor terkecil yang ada antara indikator dengan variabel laten. Hal ini didasari oleh konsep Jogja Istimewa sendiri yang menyediakan beberapa fitur yang memang membutuhkan jaringan internet seperti login, edit profile, menambahkan komentar, pembelian tiket, mengakses menu e-lapor, mengakses menu streaming, dan beberapa menu lainnya, namun menu-menu seperti pemberian informasi pada aplikasi Jogja Istimewa tetap dapat diakses tanpa menggunakan jaringan internet seperti menu Budaya, Wisata, Layanan Publik, Belajar, Kuliner, namun pengguna tidak bisa menambahkan komentar pada setiap item yang terdapat didalamnya. 


\subsection{Rekomendasi Strategis Untuk Meningkatkan Kesuksesan Aplikasi Jogis}

Dari hasil pengolahan data serta pembahasan hasil uji hipotesis yang telah dijabarkan diketahui bahwa terdapat empat hipotesis ditolak. Aplikasi Jogja Istimewa dinyatakan sukses apabila seluruh variabel yang dikemukakan Delone dan Mclean saling berhubungan satu sama lain, namun dalam uji hipotesis yang telah dilakukan terdapat empat hipotesis yang ditolak. Untuk mencapai kesuksesan tersebut, perlu dilakukan peningkatan pada empat hubungan antar variabel yang ditolak. Untuk meningkatkan kualitas informasi yang ada pada Jogja Istimewa yaitu dengan meningkatkan keakuratan informasi sehingga pengguna dapat percaya pada informasi yang disajikan aplikasi Jogja Istimewa sehingga nantinya pengguna pastinya akan merasakan betul kualitas dari informasi yang diberikan aplikasi Jogja Istimewa dengan terus melakukan update data. Selanjutnya aplikasi Jogja Istimewa sebaiknya membuat menu untuk pengguna dapat mengeluarkan opininya agar terus menggunakan aplikasi terus menerus. Untuk meningkatkan kualitas layanan, tampilan aplikasi Jogja Istimewa perlu diperbaharui dan dibuat lebih menarik lagi. Dari pihak Diskominfo sebagai pengelola aplikasi Jogja Istimewa lebih baik untuk memberikan kontak untuk pengaduan sekaligus feedback jika terdapat kegagalan sistem pada aplikasi Jogja Istimewa dan membenahi respon tanggap dari aplikasi itu sendiri agar sesuai dengan apa yang pengguna lakukan. Untuk meningkatkan kualitas sistem tersebut, aplikasi Jogja Istimewa perlu untuk membenahi bahasa yang diberikan sistem salah satunya dengan memberi pilihan bahasa yang digunakan pada aplikasi (Bahasa Inggris atau Indonesia) untuk mencegah kebingungan pengguna dalam menggunakan aplikasi Jogja Istimewa. Selain itu, Diskominfo sebagai pengelola aplikasi Jogja Istimewa sebaiknya mengoptimalkan fitur/layanan yang ada pada aplikasi Jogja Istimewa dengan memberikan perbaikan yang cepat jika terjadi kegagalan sistem.

\section{Kesimpulan dan Saran}

Dari hasil penelitian, dapat ditarik kesimpulan bahwa aplikasi Jogja Istimewa dikatakan belum sukses dikarenakan dari hipotesis yang telah diajukan, masih ada beberapa hipotesis yang ditolak. Sedangkan aplikasi Jogja Istimewa dapat dinyatakan sukses apabila seluruh variabel yang dikemukakan Delone dan Mclean saling berhubungan satu sama lain. Berdasarkan 9 hipotesis yang diajukan, dinyatakan 5 hipotesis diterima yaitu $\mathrm{H} 2, \mathrm{H} 3, \mathrm{H} 5, \mathrm{H} 7$, dan $\mathrm{H} 9$ terbukti bernilai positif dan signifikan. Dari hasil uji hipotesis tersebut diketahui bahwa System Quality dan Service Quality penentu adanya Intention to Use. Kepuasan pengguna dipengaruhi oleh Information Quality dan Intention to Use secara signifikan. Sehingga pada akhirnya User Satisfaction mempengaruhi Net Benefit.

Dilihat dari uji hipotesis yang telah dilakukan, faktor-faktor yang menghambat kesuksesan aplikasi Jogja Istimewa berdasarkan perspektif pengguna sejauh ini yaitu dilihat dari hipotesis yang ditolak. Lalu Format of Output serta Reliability dalam variabel Information Quality dengan loading factor 0,700 dan 0,709, lalu kurangnya informasi yang menghibur. Pada variabel System Quality pada indikator Language dengan nilai 0,715 yang menyatakan bahwa pengguna tidak mudah mengerti bahasa yang diberikan aplikasi Jogja Istimewa, beberapa fungsi dan fitur pada aplikasi Jogja Istimewa tidak berjalan semestinya, dan pihak pengelola lambat untuk melakukan perbaikan jika terjadi kegagalan sistem. Selanjutnya terdapat pada Service Quality responden mengeluhkan user interface yang kurang menarik, sulit menghubungi pengelola aplikasi Jogja 
Istimewa ketika ada masalah, dan sistem Jogja Istimewa kurang dalam memberikan tanggapan sesuai dengan apa yang pengguna lakukan.

Untuk meningkatkan lagi aplikasi Jogja Istimewa diperlukan strategi rekomendasi sebagai solusi untuk faktor yang menghambat kesukesan aplikasi Jogja Istimewa. Untuk mencapai kesuksesan tersebut, maka diperlukan solusi dari faktor-faktor yang dinyatakan menghambat kesuksesan yaitu memberi informasi yang menghibur, memperbaharui tampilan user interface, memberikan kontak untuk pengaduan, membenahi respon tanggap applikasi serta memberi perbaikan yang cepat agar fitur/layanan yang diberikan dapat beroperasi secara optimal, memberi pilihan bahasa yang digunakan pengguna dalam menggunakan aplikasi.

\section{Daftar Pustaka}

[1] Aurealia, N. F., \& Siregar, K. R. (2017). Analisis Teknologi Pendukung Kinerja Dosen Meggunakan Model Task- Technology Fit (Pada Perguruan Tinggi Swasta Di Bandung Utara, 2017). E-Proceeding Of Management, 4(2), 1466-1471.

[2] Chourabi, H., Nam, T., Walker, S., Gil-Garcia, J. R., Mellouli, S., Nahon, K., Pardo, T. A., \& Scholl, H. J. (2012). Understanding Smart Cities: An Integrative Framework. Proceedings Of The Annual Hawaii International Conference On System Sciences, 2289-2297. Https://Doi.Org/10.1109/HICSS.2012.615

[3] Delone, W. H., \& Mclean, E. R. (2003). The Delone And Mclean Model Of Information Systems Success: A Ten-Year Update. Journal Of Management Information Systems, 19(4), 9-30. Https://Doi.Org/10.1080/07421222.2003.11045748

[4] Ghozali, Imam, Hengky Latan. 2015. Konsep, Teknik, Aplikasi Menggunakan Smart PLS 3.0 Untuk Penelitian Empiris. BP Undip. Semarang

[5] Ghozali, Imam. 2016. Aplikasi Analisis Multivariate Dengan Program SPSS. Edisi Kedelapan. Semarang: Badan Penerbit Universitas Diponegoro

[6] H.M., Jogiyanto; Abdillah, Willy. (2009). Konsep dan Aplikasi PLS untuk Penelitian Empiris. Yogyakarta: BPEF

[7] Jaafreh, A. B. (2017). Evaluation Information System Success: Applied Delone And Mclean Information System Success Model In Context Banking System In KSA. International Review Of Management And Business Research, 6(2), 829-845

[8] Laudon, K. C., \& Laudon, J. P. (2000). Management Information Systems: Organization and Technology in the Networked Enterprise (6th ed.). Upper Saddle River, NJ: Prentice Hall.

[9] Rahman, A., \& Hartawan Syarif, M. (2019). Evaluasi Kepuasan Pengguna Aplikasi Jogja Istimewa Interface Safe Travel Kementerian Luar Negeri Republik Indonesia Menggunakan End Pengguna Aplikasi Jogja Istimewa Computing Satisfaction (Eucs). Jurnal Teknologi Informasi ESIT, 14(2), 53-58 
[10] Safdari, R., Ghazisaeidi, M., Jebraeily, M., Masarat, E., \& Shikhtayefeh, M. (2014). Hospital Information Systems Success: A Study Based On The Model Adjusted Delone And Mclean In UMSU Hospitals Pelagia Research Library Mohamad Jebraeily Et Al Pelagia Research Library. Pelagia Research Library, 4(5), 37-41

[11] Sarasati, R., \& Madyatmadja, E. D. (2020). Evaluation Of E-Government LAKSA Services To Improve The Interest Of Use Of Applications Using Technology Acceptance Model (TAM). IOP Conference Series: Earth And Environmental Science, 426(1). Https://Doi.Org/10.1088/1755-1315/426/1/01216

[12] Yamin, Sofyan dan Heri Kurniawan. 2011. Generasi Baru Mengolah Data Penelitian dengan Partial Least Square Path Modeling : Aplikasi dengan Software XLSTAT, SmartPLS, dan Visual PLS. Salemba Infotek. Jakarta. 